\title{
Fecale microbiota transplantatie, meer dan een behandeling voor Clostridium difficile?
}

Prof. dr. Max Nieuwdorp, internist-endocrinoloog en vasculair geneeskundige, Amsterdam UMC, locatie AMC

\section{Samenvatting}

De fecale microbiota transplantatie (FMT) is een bewezen effectieve behandeling voor recidiverende Clostridium difficile-infecties. Omdat in toenemende mate duidelijk wordt dat het microbioom een belangrijke rol speelt in verschillende chronische aandoeningen, wordt FMT ook steeds vaker toegepast in studieverband bij niet-infectieuze aandoeningen.

De procedure wordt meestal uitgevoerd middels het overbrengen van bewerkte dikke darminhoud van een gezonde donor via het duodenum met een sonde of het coecum met behulp van een colonoscoop maar is continu aan innovatie onderhevig. FMT is een oude behandeling, reeds in de $4 \mathrm{e}$ eeuw zijn er Chinese verslagen van 'gele soep' waarmee dysenterie werd behandeld en soortgelijke praktijken zijn ook beschreven in de Tweede Wereldoorlog. Omdat bij FMT niet alleen bacteriën, maar ook virussen, schimmels en zelfs humane cellen worden overgebracht is nog niet precies duidelijk hoe FMT werkt, en het werkingsmechanisme verschilt waarschijnlijk per aandoening en welk dieet de ontvanger van de FMT gebruikt.

\section{Inleiding}

Verstoring van de samenstelling van het microbioom wordt dysbiosis genoemd en wordt gelinkt aan tal van chronische aandoeningen. Het is vooral voor pseudomembraneuze colitis door overgroei van Clostridium difficile duidelijk dat dysbiosis in de dikke darm deze ziekte veroorzaakt en dat een herstel van microbiota door fecale microbiota transplantatie (FMT) een effectieve behandeling is om deze ziekte te genezen. ${ }^{4}$

De ontwikkeling van de FMT heeft een lange aanlooptijd gehad. FMT als behandeling van dysenterie en diarree werd reeds beschreven in de $4 \mathrm{e}$ eeuw, waarbij de Chinese arts Ge Hong met een zogenaamde 'gele soep' dysenterie behandelde. In 16e eeuw beschreef de Chinese arts Li Shizhen verschillende fecale suspensies voor de behandeling van gastro-intestinale aandoeningen als obstipatie, braken en buikpijn. ${ }^{5}$ In de Tweede Wereldoorlog gebruikten Duitse 
soldaten in Noord-Afrika kamelenfeces om dysenterie te behandelen op advies van de lokale bevolking. In 1958 werd een van de belangrijkste stappen gezet voor de toepassing van FMT in de huidige vorm. Dr. Ben Eiseman, een Amerikaans chirurg, was de eerste die klysma's met fecale suspensies voorschreef voor pseudomembraneuze colitis (nu wel bekend als Clostridium difficile-infecties). Sindsdien zijn er veel artikelen verschenen om deze procedure verder te optimaliseren. In dit overzicht zal ik een overzicht geven hoe de FMT meestal wordt uitgevoerd, waarbij een belangrijke caveat is dat de procedure nog meer gestandaardiseerd moet worden. ${ }^{5}$ Verder zal aan bod komen welke voorzorgsmaatregelen belangrijk zijn en waar de FMT nu en in de toekomst een toepassing kan hebben buiten de behandeling van recidiverende Clostridium difficile-infecties.

\section{Bereiding en toedieningsvormen}

De procedures om fecaal materiaal van de donor geschikt te maken voor transplantatie verschillen tussen de verschillende publicaties die op dit moment uitkomen, waarbij het veld op dit moment nog een compromis probeert te sluiten tussen optimalisatie en standaardisatie van de procedure. Het basisprincipe komt neer op het volgende: meestal worden verse feces in suspensie gebracht, waardoor ze kunnen worden toegediend in het duodenum, het rectum of coecum. Hierbij wordt meestal feces gemixt met isotoon $\mathrm{NaCl}$ en gefilterd. Een belangrijke limiet bij deze procedure is dat de anaerobe bacteriën blootgesteld kunnen worden aan de zuurstof in kamerlucht, met name bij het mixen van de feces. Hierbij kan een gedeelte van de vitaliteit van het microbioom verloren gaan als hier geen rekening mee wordt gehouden. Verder is het redelijk onpraktisch een donor op te roepen om vers materiaal in te laten leveren. Daarom wordt er ook geïnvesteerd in procedures waarbij fecaal materiaal wordt ingevroren in een biobank. Voor de behandeling van recidiverende Clostridium difficile lijkt FMT via deze procedure even effectief als met vers fecaal materiaal ${ }^{6}$, maar of de veranderingen in samenstelling door het vries-dooi-effect relevant zijn voor het toepassen van FMT's bij chronische aandoeningen is minder duidelijk. Deze verschillen in voorbewerkingen vormen belangrijke caveats bij de interpretatie van FMT-onderzoeken. Inmiddels wordt er zelfs onderzoek gedaan of er met voorbehandelingen van feces de samenstelling van het microbioom te beïnvloeden is om zo het effect van de FMT juist te vergroten. ${ }^{7}$

Voordat het transplantaat wordt toegediend, vindt er meestal een voorbehandeling van de dikke darm plaats om de engraftment van de microbiota te verbeteren. Hierbij is darmlavage met bijvoorbeeld macrogol een veelgebruikte procedure waarbij de eigen overgebleven dysbiotische microbiota zoveel mogelijk worden weggespoeld zodat de vrijgekomen niche zoveel mogelijk wordt overgenomen door het transplantaat. ${ }^{4} \mathrm{Bij}$ aandoeningen als colitis ulcerosa, waarbij er naast dysbiosis ook mogelijk bacteriën aanwezig zijn die de ziekte 
actief beïnvloeden, lijkt een voorbehandeling met antibiotica de effectiviteit van FMT in deze aandoening te vergroten. ${ }^{8}$

In Amerika is het toedienen van FMT's veelal een procedure die per colonoscoop wordt uitgevoerd met toedienen van het transplantaat in het coecum nabij het terminale ileum. In Europa, en ieder geval in ons centrum, is toediening per duodenumsonde de methode van voorkeur, omdat dit een minder belastende toedieningsweg is dan per colonoscopie. Er wordt ook onderzoek gedaan of het toedienen van capsules waarin het microbioom van de donor verpakt is, geschikt zijn om orale FMT's uit te voeren ${ }^{9}$, waarbij invasieve technieken om de fecale microbiota op plek van bestemming te krijgen vervallen. Dit is een belangrijke innovatie omdat de toepasbaarheid van FMT hierdoor aanzienlijk verbreed zou kunnen worden en ook een grotere rol zou kunnen spelen voor eventuele onderhoudsbehandelingen bij chronische aandoeningen, en niet alleen als remissie-inductiebehandeling bij bijvoorbeeld refractaire Clostridium difficile of inflammatoire darmziekten.

\section{Bijwerkingen en veiligheid}

FMT's zijn in de huidige vorm geurloze en smaakloze, en relatief veilige procedures. Echter, een invloedrijke publicatie in de NEJM heeft recent beschreven dat twee mensen zijn overleden na FMT door infectie met multiresistente ziekteverwekkers. ${ }^{10}$ Hoewel een immuungecompromiteerde status een rol heeft gespeeld in deze uitkomst, is er door deze publicatie nog meer aandacht gekomen voor een zorgvuldige screening van donoren (op onder andere parasieten, multiresistente bacteriën en HIV, Hepatitis B en C et cetera) voordat de FMT plaatsvindt. Welke verwekkers kosteneffectief zijn om op te nemen in de screening is nog onderhevig aan een evaluerend debat. Op het moment dat dit artikel verschijnt zal de wereld waarschijnlijk ook nog steeds in de greep zijn van de COVID-19-pandemie. Dit heeft ook gevolgen voor eventuele behandelingen met FMT, omdat we weten dat mensen asymptomatisch kunnen zijn als ze met SARS-CoV-2 zijn besmet (het virus dat de ziekte COVID-19 veroorzaakt), en SARS-CoV-2 aangetoond is in de ontlasting van mensen die COVID-19 hebben doorgemaakt. ${ }^{11}$ Mogelijk zal SARS-CoV-2 derhalve worden opgenomen in de screening die vooraf aan FMT plaatsvindt.

Een opzienbarende bijwerking van FMT kan ook zijn dat bepaalde onverwachte donoreigenschappen overgedragen kunnen worden naar de ontvanger. Zo werd een casus beschreven van een slanke patiënte die een FMT onderging van een donor met obesitas en hierna zelf ook overgewicht ontwikkelde. ${ }^{12} \mathrm{Wij}$ hebben zelf ook een casus beschreven van een patiënte met anorexia nervosa die in gewicht aankwam na FMT. ${ }^{13}$ Mogelijk zijn andere donoreigenschappen ook overdraagbaar met FMT, hierbij kan zelfs gedacht worden aan sociaal gedrag en voedselvoorkeuren. ${ }^{14}$ 
Omdat FMT voor behandeling van recidiverende Clostridium difficile zó effectief bleek dat studies vroegtijdig werden beëindigd ${ }^{4}$, is door kleine groepsgroottes het schatten van zeldzame bijwerkingen uit deze trials lastig. Voor chronische aandoeningen zal hier meer aandacht voor komen. Dit is ook relevant voor het gegeven dat er op internet instructies te vinden zijn voor het uitvoeren van doe-het-zelf-FMT's. Deze zijn met oog op veiligheid van uw patiënten niet aan te raden.

\section{Chronische ziekten waarbij gunstige effecten van FMT zijn beschreven}

Een korte search op https://clinicaltrials.gov/ toont aan dat er inmiddels bijna geen aandoening meer is waarin FMT niet onderzocht wordt als een potentiële behandeling. Het voert derhalve te ver alle aandoeningen te bespreken waarbij FMT overwogen wordt als potentiële behandeling. Dit overzicht beperkt zich derhalve tot de aandoeningen waarbij recent opzienbarende nieuwe inzichten zijn geboekt.

\section{Cardio-metabole ziekten}

De opvallende bevinding dat transplantatie van een donor met overgewicht het gewicht van een slanke ontvanger zou kunnen beïnvloeden heeft ertoe geleid dat we ons afvroegen of het omgekeerde ook opgaat, kan een FMT van een slanke donor het metabolisme van insulineresistente mensen met overgewicht beïnvloeden? Dit bleek inderdaad het geval, FMT van slanke donoren verbeterde de insulinegevoeligheid van obese mensen met insulineresistentie. ${ }^{15}$ Het was hierbij opvallend dat het uitgangsmicrobioom bepaalde in welke mate deze behandeling een gunstig effect had. Voor het metabool syndroom is de FMT te arbeidsintensief en belastend om een reguliere rol in de behandeling in cardio-metabole ziekten. De FMT is hierbij vooral van onschatbare waarde als researchtool om veelbelovende microbiota en metabolieten te identificeren.

\section{Inflammatoire darmziekten}

Er bestond ook al enige tijd de hypothese dat microbiota een belangrijke rol spelen in het ontstaan van inflammatoire darmziekten. FMT-studies die deze hypothese exploreren hebben opvallende resultaten geboekt bij de remissieinductie van colitis ulcerosa, maar het is nog niet duidelijk hoe duurzaam deze effecten zijn, en hoe veilig deze behandeling is in patiënten die doorgaans enige vorm van immunosuppressiva gebruiken. ${ }^{16}$ In het prikkelbaredarmsyndroom zijn de effecten van FMT niet eenduidig en worden zowel negatieve als positieve studies beschreven. ${ }^{17}$

\section{Maligniteiten}

In de behandeling van kanker neemt immunotherapie steeds meer een centrale rol in. De samenstelling van het microbioom lijkt in belangrijke mate de 
anti-tumorresponse te bepalen van checkpointremmers, in ieder geval bij het melanoom. ${ }^{18} \mathrm{Op}$ basis hiervan worden nu verschillende klinische studies uitgevoerd met FMT's van patiënten die een goede anti-tumorrespons hebben laten zien, naar patiënten die de behandeling nog moeten krijgen. Binnen de hematologie bestaat een soortgelijke interesse voor FMT, waar samenstelling van het microbioom als een belangrijke voorspeller van mortaliteit werd getoond na allogene stamceltransplantatie. ${ }^{19}$ Het ligt voor de hand dat uit deze belangrijke bevinding FMT-studies zullen volgen om de prognose na stamceltransplantatie te verbeteren.

\section{Neurologische aandoeningen}

Wellicht het meest opzienbarende inzicht rondom het microbioom is de observatie dat de samenstelling van het microbioom samenhangt met verschillende gedragskenmerken, recent samengevat in het gezaghebbende journal Science. ${ }^{14}$ Deze inzichten hebben zelfs geleid tot een klinische studie waarbij een FMT is toegepast om kinderen met een autismespectrumstoornis te behandelen, dit gaf bemoedigende resultaten. ${ }^{20}$ Deze studie is ook een goed voorbeeld van de mate waarin het FMT-protocol kan worden uitgebreid, met voorbehandeling met orale vancomycine, en bewerking van het transplantaat tot dit vrijwel exclusief bacteriën bevatte. Een belangrijke limitatie bij deze en vele andere FMT-studies is dat ze meestal openlabel zijn en kleine groepen bevatten. Hierdoor kunnen deze studies vatbaar zijn voor bias, vooral als er subjectieve symptomen worden onderzocht. Deze veelbelovende resultaten zijn dus toe aan replicatie. Verder wordt FMT ook overwogen in neurodegeneratieve aandoeningen als de ziekte van Parkinson, waarbij proefdierwerk suggereert dat FMT gunstig effect zou kunnen hebben op deze aandoening.

\section{Maar hoe werkt FMT?}

Bij Clostridium difficile lijkt FMT vooral te werken via een herstel van de diversiteit van het microbioom. Het lijkt er dan ook op dat de procedure werkt, ongeacht de toedieningsroute en voorbewerking van het transplantaat. Voor het effect van FMT in chronische aandoeningen is deze vraag lastiger beantwoorden, omdat bij FMT niet alleen bacteriën, maar vele andere micro-organismen worden overgebracht (denk aan gisten, virussen et cetera), maar ook metabolieten en zelfs enige humane cellen. De samenstelling van het eigen microbioom én dat van de donor is dan ook nog eens sterk individueel verschillend. Ook bestaan er grote etnische verschillen in de samenstelling van het microbioom. ${ }^{21}$ Hierdoor zijn studies onderling lastig te vergelijken. Er zijn echter een aantal innovaties in opkomst om hier beter mee om te kunnen gaan. Ten eerste bieden de ongekende innovaties in moleculaire analyses van het microbioom de mogelijkheid om microbiota gedetailleerd in kaart te brengen voor en na de FMT (denk hierbij aan sequencing en metabolomics). Met geavanceerde computeranalyses (veelal op basis van machine learning) zijn we in staat de microbiota of de metabolieten die het sterkst het effect van de FMT gedreven hebben te identificeren. Door 
het microbioom van de ontvanger voor FMT in kaart te brengen, hebben we ook ontdekt dat het uitgangsmicrobioom van groot belang is voor de uiteindelijke respons op FMT, in ieder geval binnen de setting van insulineresistentie. ${ }^{15}$ Ook is er door onze groep recent onderzoek gedaan naar de rol van gezond (mediterraan) dieet op effectiviteit van donor-FMT bij patiënten met metabool syndroom ${ }^{22}$, hetgeen laat zien dat hoe gezonder de leefstijl van de patiënt (op basis van een dieet) des te minder effectief de donor FMT is op gebied van metabole veranderingen. Voor aandoeningen waarbij (herhaalde) FMT=behandelingen onpraktisch zouden zijn, is het met deze infrastructuur mogelijk microbiota en metabolieten te vinden die vervolgens als (next generation) probioticum of medicijn verder onderzocht kunnen worden.

\section{Conclusie}

De FMT heeft een belangrijke rol verworven in de behandeling van recidiverende infecties met Clostridium difficile. Er heeft zich ook veel onderzoek gericht zich op de vraag of FMT een plek verdient in de behandeling van chronische aandoeningen waarbij het microbioom een rol lijkt te spelen. Hierbij is het meeste vooruitgang geboekt bij de behandeling van colitis ulcerosa, waarbij er positieve resultaten zijn beschreven op de kans dat er remissie wordt bereikt. Op dit moment zijn geschikte donoren schaars en belangrijke innovaties liggen op termijn van de optimale donorselectie, screening en modificatie van het transplantaat om dit te verrijken met specifieke gewenste microbiota. Bovendien is er veel meer oog gekomen voor de veiligheidsaspecten van FMT. Hoewel FMT over het algemeen een veilige procedure is die goed verdragen wordt, heeft de recente publicatie in de NEJM wel aangetoond dat goede donorscreening essentieel is en dat zeker bij immuungecompromitteerde patiënten voorzichtigheid geboden is. Daarom is het uitvoeren van doe-het-zelftransplantaties zoals deze op het internet terug te vinden zijn zeker niet aan te bevelen.

Een andere belangrijke discussie die gevoerd moet worden om behandelingen gebaseerd op het microbioom te optimaliseren, is of de FMT vooral werkt via het herstellen van een zo groot mogelijke diversiteit van het microbioom, of dat FMT gunstige effecten heeft via specifieke microbiota en/of metabolieten. In dat laatste geval zijn innovaties denkbaar waarbij uiteindelijk het toedienen van probiotica en/of metabolieten de FMT vervangen voor de behandeling van chronische aandoeningen. Desalniettemin, kunnen in de toekomst behandelingen van cardio-metabole ziekten, auto-immuunziekten en infectieziekten verwacht worden waarbij het microbioom wordt ingeschakeld om de prognose van deze aandoeningen te verbeteren.

\section{Acknowlegdments}

Werk van de onderzoeksgroep van prof M. Nieuwdorp (zoals in deze publicatie genoemd) werd deels mogelijk gemaakt door een JPI-HDHL DINAMIC grant (529051011). 


\section{Take home messages}

- FMT heeft een rol verworven in de behandeling van recidiverende Clostridium difficile-infecties

- Omdat bij FMT een scala aan micro-organismen en zelfs humane cellen van de donor worden overgebracht is het nog niet precies duidelijk hoe FMT werkt.

- FMT kan mogelijk een rol gaan spelen in de behandeling van inflammatoire darmziekten, en wordt ook onderzocht in de optimalisatie van immunotherapie bij maligniteiten en in andere chronische aandoeningen

\section{Literatuur}

1. Sender R, Fuchs S, Milo R. Are We Really Vastly Outnumbered? Revisiting the Ratio of Bacterial to Host Cells in Humans. Cell. 2016 Jan 28;164(3):337-40. PubMed PMID: 26824647.

2. Gilbert JA, Blaser MJ, Caporaso JG, Jansson JK, Lynch SV, Knight R. Current understanding of the human microbiome. Nat Med. 2018 Apr 10;24(4):392-400. PubMed PMID: 29634682.

3. Zhu W, Gregory JC, Org E, Buffa JA, Gupta N, Wang Z, et al. Gut Microbial Metabolite TMAO Enhances Platelet Hyperreactivity and Thrombosis Risk. Cell. 2016 Mar 24;165(1): 111-24. PubMed PMID: 26972052. Pubmed Central PMCID: 4862743.

4. Nood E van, Vrieze A, Nieuwdorp M, Fuentes S, Zoetendal EG, de Vos WM, et al. Duodenal infusion of donor feces for recurrent Clostridium difficile. N Engl J Med. 2013 Jan 31;368(5):407-15. PubMed PMID: 23323867.

5. Zhang F, Luo W, Shi Y, Fan Z, Ji G. Should we standardize the 1,700-year-old fecal microbiota transplantation? The American journal of gastroenterology. 2012 Nov;107(11):1755; author reply p -6. PubMed PMID: 23160295.

6. Lee CH, Steiner T, Petrof EO, Smieja M, Roscoe D, Nematallah A, et al. Frozen vs Fresh Fecal Microbiota Transplantation and Clinical Resolution of Diarrhea in Patients With Recurrent Clostridium difficile Infection: A Randomized Clinical Trial. JAMA. 2016 Jan 12;315(2):142-9. PubMed PMID: 26757463.

7. Tanca A, Palomba A, Pisanu S, Addis MF, Uzzau S. Enrichment or depletion? The impact of stool pretreatment on metaproteomic characterization of the human gut microbiota. Proteomics. 2015 Oct; 15(20):3474-85. PubMed PMID: 25677681.

8. Keshteli AH, Millan B, Madsen KL. Pretreatment with antibiotics may enhance the efficacy of fecal microbiota transplantation in ulcerative colitis: a meta-analysis. Mucosal immunology. 2017 Mar;10(2):565-6. PubMed PMID: 28000680.

9. Kao D, Roach B, Silva M, Beck P, Rioux K, Kaplan GG, et al. Effect of Oral Capsule- vs Colonoscopy-Delivered Fecal Microbiota Transplantation on Recurrent Clostridium difficile Infection: A Randomized Clinical Trial. JAMA. 2017 Nov 28;318(20):1985-93. PubMed PMID: 29183074. Pubmed Central PMCID: 5820695.

10. DeFilipp Z, Bloom PP, Torres Soto M, Mansour MK, Sater MRA, Huntley MH, et al. Drug-Resistant E. coli Bacteremia Transmitted by Fecal Microbiota Transplant. N Engl J Med. 2019 Nov 21;381(21):2043-50. PubMed PMID: 31665575.

11. Gu J, Han B, Wang J. COVID-19: Gastrointestinal manifestations and potential fecal-oral transmission. Gastroenterology. 2020 Mar 3. PubMed PMID: 32142785.

12. Alang N, Kelly CR. Weight gain after fecal microbiota transplantation. Open forum infectious diseases. 2015 Jan;2(1):ofv004. PubMed PMID: 26034755. Pubmed Central PMCID: 4438885.

13. Clercq NC de, Frissen MN, Davids M, Groen AK, Nieuwdorp M. Weight Gain after Fecal 
Microbiota Transplantation in a Patient with Recurrent Underweight following Clinical Recovery from Anorexia Nervosa. Psychotherapy and psychosomatics. 2019;88(1):58-60. PubMed PMID: 30625497.

14. Sherwin E, Bordenstein SR, Quinn JL, Dinan TG, Cryan JF. Microbiota and the social brain. Science. 2019 Nov 1;366(6465). PubMed PMID: 31672864.

15. Kootte RS, Levin E, Salojarvi J, Smits LP, Hartstra AV, Udayappan SD, et al. Improvement of Insulin Sensitivity after Lean Donor Feces in Metabolic Syndrome Is Driven by Baseline Intestinal Microbiota Composition. Cell Metab. 2017 Oct 3;26(4):611-9 e6. PubMed PMID: 28978426.

16. Paramsothy S, Paramsothy R, Rubin DT, Kamm MA, Kaakoush NO, Mitchell HM, et al. Faecal Microbiota Transplantation for Inflammatory Bowel Disease: A Systematic Review and Meta-analysis. Journal of Crohn's \& colitis. 2017 Oct 1;11(10):1180-99. PubMed PMID: 28486648.

17. Wortelboer K, Nieuwdorp M, Herrema H. Fecal microbiota transplantation beyond Clostridioides difficile infections. EBioMedicine. 2019 Jun;44:716-29. PubMed PMID: 31201141. Pubmed Central PMCID: 6606746.

18. Gopalakrishnan V, Spencer CN, Nezi L, Reuben A, Andrews MC, Karpinets TV, et al. Gut microbiome modulates response to anti-PD-1 immunotherapy in melanoma patients. Science. 2018 Jan 5;359(6371):97-103. PubMed PMID: 29097493. Pubmed Central PMCID: 5827966.

19. Peled JU, Gomes ALC, Devlin SM, Littmann ER, Taur Y, Sung AD, et al. Microbiota as Predictor of Mortality in Allogeneic Hematopoietic-Cell Transplantation. N Engl J Med. 2020 Feb 27;382(9):822-34. PubMed PMID: 32101664.

20. Kang DW, Adams JB, Gregory AC, Borody T, Chittick L, Fasano A, et al. Microbiota Transfer Therapy alters gut ecosystem and improves gastrointestinal and autism symptoms: an open-label study. Microbiome. 2017 Jan 23;5(1):10. PubMed PMID: 28122648. Pubmed Central PMCID: 5264285 .

21. Deschasaux M, Bouter KE, Prodan A, Levin E, Groen AK, Herrema H, et al. Depicting the composition of gut microbiota in a population with varied ethnic origins but shared geography. Nat Med. 2018 Oct;24(10):1526-31. PubMed PMID: 30150717.

22. A.M. Koopen, A. Prodan, A.K. Groen, M. Nieuwdorp. Lack of synergetic effect in combining mediterranean diet and donor FMT on glucose metabolism in subjects with metabolic syndrome. [manuscript submitted]. 